\title{
The effect of triptorelin and leuprolide on the level of sex hormones in girls with central precocious puberty and its clinical efficacy analysis
}

\author{
Lan Wang ${ }^{1}$, Qun Jiang ${ }^{1}$, Manman Wang ${ }^{1}$, Jiawang Xu' ${ }^{1}$, Juhua Jin ${ }^{2}$ \\ ${ }^{1}$ Department of Pediatrics, Xiaoshan Hospital Affiliated to Hangzhou Normal University, Hangzhou, China; ${ }^{2}$ Department of Pediatrics, Tongde \\ Hospital of Zhejiang Province, Hangzhou, China \\ Contributions: (I) Conception and design: L Wang, J Jin; (II) Administrative support: L Wang; (III) Provision of study materials or patients: L Wang, J \\ Jin; (IV) Collection and assembly of data: All authors; (V) Data analysis and interpretation: L Wang, J Jin; (VI) Manuscript writing: All authors; (VII) \\ Final approval of manuscript: All authors. \\ Correspondence to: Juhua Jin. Department of Pediatrics, Tongde Hospital of Zhejiang Province, 234 Gucui Road, Xihu District, Hangzhou 310012, \\ China. Email: zjuwljjh@163.com.
}

Background: This study aimed to explore the effects of triptorelin and leuprolide on serum hormone levels and the clinical efficacy of girls with idiopathic central precocious puberty (ICPP).

Methods: Retrospective analysis was performed on 128 girls with ICPP who were diagnosed and treated in our hospital from January 2017 to January 2020, including 71 girls in the leuprolide group and 57 girls in the triptorelin group. The differences of serum sex hormone level, ovarian volume, uterine volume, follicle diameter, bone age, growth rate (height change within half a year), maturity (bone age/living age), and other aspects between the two groups of girls were compared.

Results: Before treatment, there was no significant difference in the baseline levels of sex hormones [estradiol (E2), luteinizing hormone ( $\mathrm{LH})$, follicle-stimulating hormone (FSH)] between the triptorelin group and the leuprorelin group $(\mathrm{P}>0.05)$. After 1 year of treatment, serum levels of E2 and FSH in the triptorelin group were lower than those in the leuprolide group $(\mathrm{P}<0.05)$. There was no significant difference in $\mathrm{LH}$ levels between the two groups after 1 year of treatment $(\mathrm{P}>0.05)$. At baseline, there was no significant difference in the ovarian volume, follicle diameter, and uterine volume between the triptorelin group and the leuprolide group $(\mathrm{P}>0.05)$. After 1 year of treatment, the ovarian volume, follicle diameter, and uterine volume of the girls in the triptorelin group were all lower than those in the leuprolide group $(\mathrm{P}<0.05)$. Before treatment, there was no statistical difference in bone age, growth rate, and maturity between the triptorelin group and the leuprolide group $(\mathrm{P}>0.05)$. After 1 year of treatment, the growth rate and maturity of participants in the triptorelin group were lower than those in the leuprolide group $(\mathrm{P}<0.05)$. There was no significant difference in bone age between the two groups after 1 year of treatment $(\mathrm{P}>0.05)$.

Conclusions: For girls with ICPP, triptorelin is superior to leuprolide in reducing sex hormone level, reducing uterine volume, follicle diameter, ovarian volume, slowing down the growth rate, and decreasing maturity. Triptorelin should be selected as a priority for the treatment of girls with ICPP.

Keywords: Central precocious puberty; leuprolide; triptorelin; sex hormones

Submitted Jul 07, 2021. Accepted for publication Aug 26, 2021.

doi: $10.21037 /$ tp-21-352

View this article at: https://dx.doi.org/10.21037/tp-21-352 


\section{Introduction}

Precocious puberty refers to the appearance of secondary sexual characteristics in female children before 8 years old and male children before 9 years old $(1,2)$. Central precocious puberty is due to the hypothalamus prematurely increasing the secretion and release of gonadotropinreleasing hormone $(\mathrm{GnRH})$, which activates the function of the gonadal axis in advance. The incidence of central precocious puberty is about $1 / 5,000$ to $1 / 10,000$. According to different causes, it can be divided into idiopathic and secondary. Idiopathic central precocious puberty (ICPP) accounts for about $80 \%$ to $90 \%$ of the total $(3,4)$. The incidence rate of precocious puberty is increasing year by year throughout the world, which may be related to the changes in the living environment and exogenous hormones $(5-7)$. The incidence rate of precocious puberty in girls is higher than that in boys. The specific clinical manifestations of the disease are rapid increases in weight and height, and the appearance of axillary and pubic hair. In girls, rapid breast growth and early menarche also present. In boys, testicular development and penis growth become increased. Precocious puberty can be divided into central precocious puberty, peripheral precocious puberty, and partial precocious puberty. The disease affects children's bodies and causes severe psychological problems, resulting in mental disorders or behavioral abnormalities (8). Therefore, clinicians attach great importance to the disease. In China, triptorelin and leuprolide are the most commonly used in GnRH analogues, but there is no uniform standard or opinion on which drug, dosage and regimen are preferred. Triptorelin and leuprolide are commonly used in treating ICPP, but comparative analysis of the two drugs has been scarce. This study compared the effects of triptorelin and leuprolide on serum hormone levels and clinical efficacy in girls with ICPP, thus providing a reference for clinical medication decision-making. We present the following article in accordance with the STROBE reporting checklist (available at https://dx.doi.org/10.21037/tp-21-352).

\section{Methods}

\section{Case collection}

We performed a retrospective analysis of 128 girls with ICPP diagnosed and treated in our hospital from January 2017 to January 2020, including 71 girls treated with triptorelin and 57 girls treated with leuprolide. The inclusion criteria were as follows: (I) informed consent signed by the legal guardian of the child; (II) the child met the diagnostic criteria of ICPP, referring to the "Recommendations on the diagnosis and treatment of central (true) precocious puberty" (Chinese Medical Association, 2017 edition); (III) had not received any previous treatment. The exclusion criteria were as follows: (I) combined with other cardiovascular and cerebrovascular diseases, liver or kidney dysfunction; (II) central precocious puberty caused by space-occupying tumor, central nervous system infection, injury, or dysplasia; (III) had participated in other clinical studies within 3 months. All procedures performed in this study involving human participants were in accordance with the Declaration of Helsinki (as revised in 2013). The study was approved by the Ethics Committee of Xiaoshan Hospital Affiliated to Hangzhou Normal University (No.: 2020-037) and informed consent was taken from all the patients.

\section{Therapeutic method}

The children in the triptorelin group were injected tripraline acetate subcutaneously at a dose of $100 \mu \mathrm{g} / \mathrm{kg}$ once a month. The children in the leuprolide group were injected with leuprolide acetate under the skin. The initial dose was $90 \mu \mathrm{g} / \mathrm{kg}$ once a month, and after 3 months of continuous subcutaneous injection, they received an adjusted dose of $60-80 \mu \mathrm{g} / \mathrm{kg}$. The two groups were treated at least 12 months.

\section{Observation index}

The two groups were followed up for more than 1 year. The main outcome measures were as follows: (I) determination of serum sex hormones before and after treatment for 1 year. The venous blood of the girls was collected. The contents of estradiol (E2), luteinizing hormone (LH), and folliclestimulating hormone (FSH) in serum were determined by immunoluminescence assay. (II) The changes of reproductive organs: ovarian volume, follicle size, and uterine volume of the two groups were measured by B-ultrasound before treatment and 1 year after treatment. (III) The height, weight, bone age, growth rate (height change within half a year), and maturity (bone age/actual age) were measured before and 1 year after treatment. The calculation formula referred to the 7th edition of "Practical pediatrics".

\section{Statistical analysis}

The data were analyzed using R software (http://www. 
Table 1 Comparative analysis of the general situation of two groups of ICPP girls

\begin{tabular}{|c|c|c|c|c|}
\hline General information & Triptorelin group $(n=57)$ & Leuprolide group $(n=71)$ & $\mathrm{t}$ & $P$ value \\
\hline Height $(\mathrm{cm})$ & $134.4 \pm 6.2$ & $133.7 \pm 5.8$ & 0.658 & $>0.05$ \\
\hline Weight (kg) & $24.6 \pm 4.2$ & $25.8 \pm 6.3$ & -1.234 & $>0.05$ \\
\hline Bone age (years) & $9.24 \pm 0.66$ & $9.19 \pm 0.73$ & 0.402 & $>0.05$ \\
\hline
\end{tabular}

ICPP, idiopathic central precocious puberty.

Table 2 Comparative analysis of serum sex hormones in two groups of ICPP girls

\begin{tabular}{|c|c|c|c|c|}
\hline Sex hormones & Triptorelin group $(n=57)$ & Leuprolide group $(\mathrm{n}=71$ ) & $\mathrm{t}$ & $P$ value \\
\hline Before treatment & $33.45 \pm 16.39$ & $34.76 \pm 15.11$ & -0.469 & $>0.05$ \\
\hline 1 year after & $21.76 \pm 10.21$ & $15.43 \pm 9.38$ & 3.648 & $<0.05$ \\
\hline \multicolumn{5}{|l|}{$\mathrm{LH}$} \\
\hline 1 year after & $5.10 \pm 2.31$ & $4.42 \pm 2.55$ & 1.563 & $>0.05$ \\
\hline \multicolumn{5}{|l|}{ FSH } \\
\hline Before treatment & $15.02 \pm 6.43$ & $14.31 \pm 5.72$ & 0.660 & $>0.05$ \\
\hline 1 year after & $5.64 \pm 2.07$ & $4.47 \pm 1.91$ & 3.318 & $<0.05$ \\
\hline
\end{tabular}

ICPP, idiopathic central precocious puberty; E2, estradiol; LH, luteinizing hormone; FSH, follicle-stimulating hormone.

$\mathrm{R}$-project.org/) and related $\mathrm{R}$ packages. The count data were expressed in the form of a percentage $[\mathrm{n}(\%)]$, and the chi-square test was used. Measurement data were expressed as mean \pm standard deviation $(\bar{x} \pm s)$, the $t$-test was used, and $\mathrm{P}<0.05$ indicated statistical significance.

\section{Results}

Comparative analysis of the general situation of two groups of ICPP girls

Before treatment, there was no significant difference in age, height, weight and bone age between the two groups $(\mathrm{P}>0.05)$ (Table 1).

\section{Comparative analysis of serum sex hormones in the two participant groups}

Before treatment, there was no significant difference in the levels of sex hormones (E2, LH, FSH) between the two groups $(\mathrm{P}>0.05)$. After 1 year of treatment, the levels of $\mathrm{E} 2$ and FSH in serum of participants in the triptorelin group were lower than those in the leuprolide group, with statistical significance $(\mathrm{P}<0.05)$, but there was no statistical difference in $\mathrm{LH}$ between the two groups after 1 year of treatment $(\mathrm{P}>0.05)$ (Table 2).

\section{Comparative analysis of the changes of reproductive organs in two groups}

Before treatment, there was no significant difference in ovarian volume, follicle diameter, and uterine volume between the triptorelin group and the leuprolide group $(\mathrm{P}>0.05)$. After 1 year of treatment, the ovarian volume, follicle diameter, and uterine volume of the girls in the triptorelin treatment group were smaller than those in the leuprolide group, with statistical significance $(\mathrm{P}<0.05)$ (Table 3).

\section{Comparative analysis of growth indexes of two groups}

Before treatment, there was no significant difference in bone age, growth rate, and maturity between the triptorelin group and the leuprolide group $(\mathrm{P}>0.05)$. After 1 year of 
Table 3 Comparative analysis of the changes of reproductive organs in two groups of ICPP girls

\begin{tabular}{|c|c|c|c|c|}
\hline Reproductive organs & Triptorelin group $(n=57)$ & Leuprolide group $(\mathrm{n}=71)$ & $\mathrm{t}$ & $P$ value \\
\hline Before treatment & $2.71 \pm 1.49$ & $3.01 \pm 1.11$ & -1.305 & $>0.05$ \\
\hline 1 year after & $1.97 \pm 0.98$ & $1.56 \pm 0.83$ & 2.562 & $<0.05$ \\
\hline \multicolumn{5}{|l|}{ Follicle diameter (mm) } \\
\hline 1 year after & $5.47 \pm 1.39$ & $4.18 \pm 1.51$ & 4.975 & $<0.05$ \\
\hline \multicolumn{5}{|l|}{ Uterine volume (mL) } \\
\hline Before treatment & $3.02 \pm 1.31$ & $3.43 \pm 1.47$ & -1.645 & $>0.05$ \\
\hline 1 year after & $2.38 \pm 1.07$ & $2.01 \pm 1.00$ & 2.017 & $<0.05$ \\
\hline
\end{tabular}

ICPP, idiopathic central precocious puberty.

Table 4 Comparative analysis of growth indexes of two groups of ICPP girls

\begin{tabular}{|c|c|c|c|c|}
\hline Growth indexes & Triptorelin group $(n=57)$ & Leuprolide group $(n=71)$ & $\mathrm{t}$ & $P$ value \\
\hline Before treatment & $9.24 \pm 0.66$ & $9.19 \pm 0.73$ & 0.402 & $>0.05$ \\
\hline 1 year after & $9.11 \pm 0.61$ & $8.46 \pm 0.44$ & 6.996 & $>0.05$ \\
\hline \multicolumn{5}{|c|}{ Growth rate (cm/half year) } \\
\hline 1 year after & $3.24 \pm 0.31$ & $2.14 \pm 0.27$ & 21.442 & $<0.05$ \\
\hline \multicolumn{5}{|l|}{ Maturity } \\
\hline Before treatment & $1.31 \pm 0.14$ & $1.27 \pm 0.19$ & 1.326 & $>0.05$ \\
\hline 1 year after & $1.24 \pm 0.17$ & $1.11 \pm 0.11$ & 5.226 & $<0.05$ \\
\hline
\end{tabular}

ICPP, idiopathic central precocious puberty.

treatment, the growth rate and maturity of girls in the triptorelin treatment group were lower than those in the leuprolide treatment group, with statistical significance $(\mathrm{P}<0.05)$, but there was no statistical difference in bone age between the two groups after 1 year of treatment $(\mathrm{P}>0.05)$ (Table 4).

\section{Discussion}

Precocious puberty is a common endocrine disease, and its incidence rate in China is increasing annually (9). The increase may be related to the improvement of our people's living standards and rich material life. The increase of children's food intake, increase of hormone disrupting substances in daily life, and the excessive nutrition of children are the main reasons for precocious puberty $(10-12)$. Precocious puberty involves the premature arrest of children's bone growth, significantly impacts children's height, and causes a series of psychological problems such as early sexual behavior and psychosexual disorders (13-15). Epidemiological studies have shown that about $18 \%$ of children experience precocious puberty, and its incidence in girls is 5 times that of boys in China. How to administer drugs reasonably is one of the clinical problems presented by precocious puberty.

Triptorelin and leuprolide are GnRH analogs. Their pharmacological mechanism is to competitively bind to $\mathrm{GnRH}$ receptors to reduce gonadotropin secretion by the pituitary gland. They are mainly used to treat endometriosis, hysteromyoma, prostate cancer, central 
precocious puberty, and other diseases (16-18). Triptorelin is 35 times more effective than GnRH and has a long halflife, so triptorelin can maintain the therapeutic level for a long time. After triptorelin was stopped, its inhibitory effect on the pituitary gland disappeared quickly. Leuprolide has a strong affinity with GnRH receptors, which not only inhibits the pituitary gland and reduces gonadotropins, but also reduces the sensitivity of the ovaries and testes to gonadotropins. Studies have also shown that triptorelin and leuprolide treatment in children with central precocious puberty can lead to increased fat mass and an increased risk of obesity in the future (19).

This study found that before treatment, there was no significant difference in age, height, weight, bone age, sex hormone (E2, LH, FSH), ovarian volume, follicle diameter, uterine volume, bone age, growth rate, and maturity between the triptorelin treatment group and leuprolide treatment group. After 1 year of treatment, the serum E2 and FSH levels in the triptorelin group were lower than those in the leuprolide group, but there was no significant difference in LH between the two groups. After 1 year of treatment, the ovarian volume, follicle diameter, and uterine volume in the triptorelin group were smaller than those in the leuprolide group; at the same time, the growth rate and maturity of girls in the triptorelin treatment group were lower than those in the leuprorelin treatment group $(\mathrm{P}<0.05)$, but there was no significant difference in bone age between the two groups after 1 year of treatment $(\mathrm{P}>0.05)$. Previous studies have mostly compared the clinical effect of leuprorelin and medroxyprogesterone on the disease and compared leuprorelin and medroxyprogesterone and monotherapy. The results of other reliable studies do not align with our results. This study was a retrospective analysis, and the sample size was small. The findings of this study require verification through larger sample sized, prospective studies.

We recommend that triptorelin be used for the treatment of girls with ICPP. Dosage and schedule of medication need to emphasize the principle of individualization. For children who cannot be well controlled or cannot achieve the expected treatment goals, we recommend shortening the interval between medications or increasing the dosage of medications. During treatment, the child's development, growth rate, hormone level, and bone age should be closely monitored, and the function of the gonadal axis should be assessed. In treatment, attention should also be paid to the social and psychological impact of the children and their parents, and early psychological evaluation and psychological intervention should be carried out.

\section{Acknowledgments}

Funding: None.

\section{Footnote}

Reporting Checklist: The authors have completed the STROBE reporting checklist. Available at https://dx.doi. org/10.21037/tp-21-352

Data Sharing Statement: Available at https://dx.doi. org/10.21037/tp-21-352

Conflicts of Interest: All authors have completed the ICMJE uniform disclosure form (available at https://dx.doi. org/10.21037/tp-21-352). The authors have no conflicts of interest to declare.

Ethical Statement: The authors are accountable for all aspects of the work in ensuring that questions related to the accuracy or integrity of any part of the work are appropriately investigated and resolved. All procedures performed in this study involving human participants were in accordance with the Declaration of Helsinki (as revised in 2013). The study was approved by the Ethics Committee of Xiaoshan Hospital Affiliated to Hangzhou Normal University (No.: 2020-037) and informed consent was taken from all the patients.

Open Access Statement: This is an Open Access article distributed in accordance with the Creative Commons Attribution-NonCommercial-NoDerivs 4.0 International License (CC BY-NC-ND 4.0), which permits the noncommercial replication and distribution of the article with the strict proviso that no changes or edits are made and the original work is properly cited (including links to both the formal publication through the relevant DOI and the license). See: https://creativecommons.org/licenses/by-nc-nd/4.0/.

\section{References}

1. Latronico AC, Brito VN, Carel JC. Causes, diagnosis, and treatment of central precocious puberty. Lancet Diabetes Endocrinol 2016;4:265-74.

2. Aguirre RS, Eugster EA. Central precocious puberty: from genetics to treatment. Best Pract Res Clin Endocrinol 
Metab 2018;32:343-54.

3. Soriano-Guillén L, Argente J. Central precocious puberty, functional and tumor-related. Best Pract Res Clin Endocrinol Metab 2019;33:101262.

4. Yang H, Luo S, Liang X, et al. The association between family impact and health-related quality of life of children with idiopathic central precocious puberty in Chongqing, China. Health Qual Life Outcomes 2021;19:171.

5. Brito VN, Spinola-Castro AM, Kochi C, et al. Central precocious puberty: revisiting the diagnosis and therapeutic management. Arch Endocrinol Metab 2016;60:163-72.

6. Chen M, Eugster EA. Central precocious puberty: update on diagnosis and treatment. Paediatr Drugs 2015;17:273-81.

7. Cantas-Orsdemir S, Eugster EA. Update on central precocious puberty: from etiologies to outcomes. Expert Rev Endocrinol Metab 2019;14:123-30.

8. Durá-Travé T, Ortega Pérez M, Ahmed-Mohamed L, et al. Central precocious puberty in girls: Diagnostic study and auxological response to triptorelin treatment. Endocrinol Diabetes Nutr (Engl Ed) 2019;66:410-6.

9. Fu J, Zhang J, Chen R, et al. Long-term outcomes of treatments for central precocious puberty or early and fast puberty in Chinese girls. J Clin Endocrinol Metab 2020;105:dgz027.

10. Chirico V, Lacquaniti A, Salpietro V, et al. Central precocious puberty: from physiopathological mechanisms to treatment. J Biol Regul Homeost Agents 2014;28:367-75.

11. Klein K, Yang J, Aisenberg J, et al. Efficacy and safety of triptorelin 6-month formulation in patients with central precocious puberty. J Pediatr Endocrinol Metab

Cite this article as: Wang L, Jiang Q, Wang M, Xu J, Jin J. The effect of triptorelin and leuprolide on the level of sex hormones in girls with central precocious puberty and its clinical efficacy analysis. Transl Pediatr 2021;10(9):2307-2312. doi: $10.21037 / \mathrm{tp}-21-352$
2016;29:1241-8.

12. Bräuner EV, Busch AS, Eckert-Lind C, et al. Trends in the incidence of central precocious puberty and normal variant puberty among children in Denmark, 1998 to 2017. JAMA Netw Open 2020;3:e2015665.

13. Léger J, Carel JC. Central precocious puberty management and long-term outcomes. Eur Endocrinol 2015;11:45-6.

14. Neeman B, Bello R, Lazar L, et al. Central precocious puberty as a presenting sign of nonclassical congenital adrenal hyperplasia: clinical characteristics. J Clin Endocrinol Metab 2019;104:2695-700.

15. Latronico AC. Challenges in monitoring GnRH analog treatment in central precocious puberty. Arch Endocrinol Metab 2020;64:103-4.

16. Klein KO, Dragnic S, Soliman AM, et al. Predictors of bone maturation, growth rate and adult height in children with central precocious puberty treated with depot leuprolide acetate. J Pediatr Endocrinol Metab 2018;31:655-63.

17. Omar AA, Nyaga G, Mungai LNW. Pseudotumor cerebri in patient on leuprolide acetate for central precocious puberty. Int J Pediatr Endocrinol 2020;2020:22.

18. Kaplowitz PB. Treatment of central precocious puberty. Curr Opin Endocrinol Diabetes Obes 2009;16:31-6.

19. Chiumello G, Brambilla P, Guarneri MP, et al. Precocious puberty and body composition: effects of GnRH analog treatment. J Pediatr Endocrinol Metab 2000;13 Suppl $1: 791-4$.

(English Language Editor: J. Jones) 